\title{
Cryotherapy: the dry benefits
}

\begin{abstract}
Cryotherapy is use of cold to decrease pain, muscle spasm and temperature to name a few. It is often used to prevent swelling and for muscle recovery following strenuous activity. Most cryotherapy devices (ice packs, ice massage and cold whirlpool) are delivered via a wet medium. Cryosauna uses a dry medium of nitrogen vapor. The patient stands in a cylinder that covers every body part except the head. The vapor is emitted for 3 minutes at a temperature of minus $250 \mathrm{~F}$. Users of cryosauna state that this treatment aids in recovery of strenuous activity. This paper will introduce the cryosauna, effects and benefits of this device and a step by step procedure used to deliver this unique form of dry cryotherapy.
\end{abstract}

Volume 2 Issue I - 2018

\section{David O Draper, Brock Roberts}

Professor of athletic training and sports medicine, Brigham

Young University, USA

Correspondence: David O Draper, Professor of athletic training and sports medicine, Brigham Young University, USA, Email David_draper@byu.edu

Received: October 14, 2017| Published: January 08, 2018

Keywords: Cryotherapy, cryosauna, arthritis, body temperature, ice packs

\section{Introduction}

Cryotherapy is the application of a device or substance with a temperature less than body temperature, thus causing heat to pass from the body to the cryotherapy device ${ }^{1,2}$ In Physical Medicine and Rehabilitation, cryotherapy is administered via ice packs, ice massage, cold whirlpool, cryokinetics, cryostretch, cold compression devices, contrast baths and ice slush. ${ }^{1-8}$ The physiological effects of cryotherapy are:
a. Vasoconstriction ${ }^{1-8}$
b. Decreased temperature ${ }^{1-8}$
c. Tissue destruction (at $-20^{\circ} \mathrm{C}$ to $\left.-70^{\circ} \mathrm{C}\right)^{9-15}$
d. Increased or decreased inflammation ${ }^{9-15}$
e. Decreased metabolism ${ }^{1,29,10,13,14}$
f. Decreased or increased pain ${ }^{1,2,5-8}$
g. Decreased nerve conduction ${ }^{1,2,16-18}$
h. Decreased blood flow ${ }^{1-8,19}$
A. Decreased muscle spasm ${ }^{1-8,20-23}$
B. Increased tissue stiffness ${ }^{1-8,21-23}$
C. Decreased arthrogenic muscle inhibition ${ }^{1-8,21-23}$
D. Decreased circulation ${ }^{1-8,24-26}$

The devices previously listed are known as spot cryotherapy, meaning they focus their energy on 1 or 2 spots on the body. Whole Body Cryotherapy includes a device referred to as cryosauna. The cryosauna involves having the patient stand in a hollow cylinder that emits a nitrogen vapor within the cylinder at 80psi from a large insulated tank. The vapor is created via a heating and cooling transfer process that the technology emits. The cold vapor is applied to the body for 1.5 to 3 minutes at -250 degrees $\mathrm{F}$ ( -156.66 degrees $\mathrm{C})$. It is a safe and healthy process that accelerates the body's natural healing powers while energizing the body and improving overall wellbeing. The 3 minute hyper-cooling process lowers the skin's temperature by 30 degrees $\mathrm{F}$ or more from baseline temperature. This accelerates muscle recovery while producing a rush of endorphins about 4-5 times normal levels. There is also a small release of dopamine into the system. This cutting-edge technology is quickly becoming a staple for professional and collegiate sports teams, often replacing the ice bath. Whole body cryotherapy has been around for decades. It originated in Japan in 1978 and then migrated into Europe. ${ }^{27}$ It was introduced in the United States in 2010. The company that pioneered Full Body Cryotherapy in the United States was CryoHealthCare located in Hollywood, California. Many sports recovery establishments are acquiring this hyper cold technology in order to help their athletes recover more effectively.

\section{Benefits of cryosauna}

Specific effects attributed to the cryosauna are:
a. Pain relief ${ }^{28}$
b. Decreased inflammation
c. Increased metabolism
d. Endorphin release
e. Healing
f. Relief of arthritic conditions
g. Relief of acute and chronic injuries ${ }^{28}$
h. Improved sense of well-being ${ }^{29}$
i. Increased venous pressure ${ }^{29,30}$
j. Exercise recovery $^{28}$
k. Burning of about 300 calories
1. Preventing muscle soreness ${ }^{29}$
m. Improved parasympathetic activity ${ }^{29}$
n. Increased stroke volume ${ }^{29,30}$
o. Enhanced running performance ${ }^{30}$
p. Decreased core body temperature ${ }^{31}$

The Juka cryosauna (Figure 1) is produced by CryoHealthCare, one of the oldest innovative cryosauna companies in the industry. Their 
most innovative sauna on the market as of 2016 allows for the patient to see the temperature at the time in the cryosauna while they are standing in the cylinder. There is another form of dry cryotherapy that uses a nitrogen vapor as its medium (spot cryotherapy). Its advantages over the cryosauna are that it is portable, easy to use and only the part that is treated will get cold. Also there is no disrobing required by the patient. The disadvantages of spot cryotherapy compared to the cryosauna are that the whole body isn't treated so there is less muscle recovery experienced from using the device.

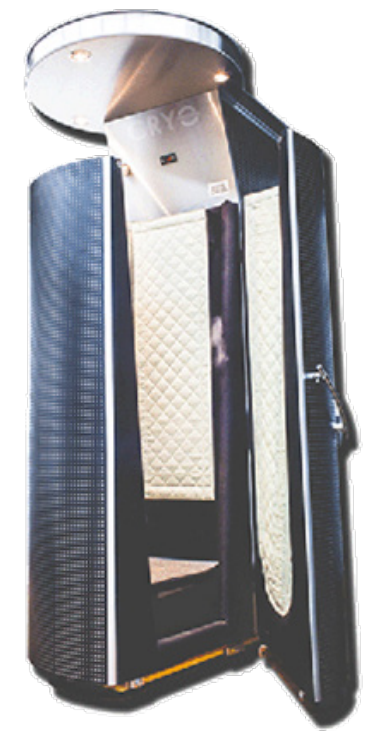

Figure I The Juka cryosauna.

\section{Application}

The following will give you a step by step experience of what to expect when coming to a Cryotherapy Spa. We will also share a few examples where the cryosauna has made a real impact.

\section{Step I}

The first thing is the need for the elements that will allow the cryosauna to get this cold (nitrogen). Nitrogen normally is a gas that will only last as a liquid inside the tank the patient resides in. There is usually about an $8 \%$ blow off each day that the nitrogen resides in the tank. Since the need for the cryosauna is liquid nitrogen it is vital that the sooner the nitrogen is used, the better it is for the company providing this benefit. There are 2 types of tanks, a large tank that rests usually outside the structural facility on a concrete slab that is designed to hold the weight of the tank when it is completely filled with nitrogen. Inside the clinic there are tanks that hold about $230 \mathrm{~L}$ per tank. There are significant benefits to utilizing this type of system, one of which is that the tank can be filled any time during the day or night which allows for there to be zero issues for the business during or after work hours. It also allows for less nitrogen waste as there is less "blow off". The cryosauna then takes about 3 to 5 minutes to prepare for the session to start.

\section{Step 2}

The client prepares for the session by changing into a robe, knee high socks, slippers and gloves. Male patients dress down to their briefs while women dress down completely, or wear a bathing suit. No metal or jewelry is to be warning in the cryosauna due to how cold the temperatures are inside the cylinder.

\section{Step 3}

When the cryosauna is ready the clinician providing the therapy helps the patient into the sauna and then raises the patient to the appropriate level (Figure 2). The patient then removes the robe and hands it to the clinician. The patient will be in the cryosauna generally between 1.5 minutes to 3 minutes. As a patient does Full Body Cryotherapy often the body regulates and is able to stay in the cryosauna longer. The most that one session can last is 3 minutes.

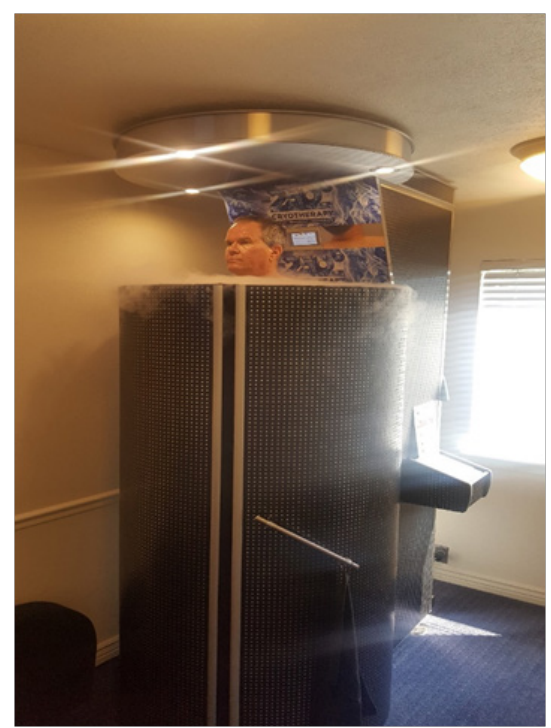

Figure 2 Patient in the cryosauna.

\section{Step 4}

When the session is over clinician cracks, the door open is slightly to allow the nitrogen vapor to release from within the chamber. The robe is then handed back to the patient and the clinician then shuts the door while the patient puts the robe back on.

\section{Step 5}

After the session it is recommended to increase the heart rate of the client through activity so that the strongest and most beneficial response takes place in the patient's body. This can be accomplished via a vibration plate, a treadmill, a stationary exercise bike, or just regular pushups, or sit-ups, etc.

\section{Indications and contraindications}

Indications specifically for cryosauna include:
a. Pain
b. Inflammation
c. Unhealed tissue
d. Arthritis
e. Lack of energy
f. Swelling
g. Muscle spasm

Contraindications for cryosauna:

a. Pregnancy 

b. Untreated hypothyroidism
c. Chronic respiratory disease
d. Severe hypertension
e. Cardiovascular disease
f. Recent stroke
g. Uncontrolled seizure
h. Fever
i. Bleeding disorders
j. Infection
k. Claustrophobia
1. Intolerance to cold
m. Incontinence

\section{Discussion}

The athletic population has been particularly interested in the potential positive effects on both minimizing muscle soreness and on recovery of muscle strength, endurance and power following training and exercise. The majority of claims are anecdotal regarding the efficacy of whole body cryotherapy. There is, however, a lack of data that supports whole body cryotherapy in its ability to reduce muscle soreness, or improve recovery after exercise. ${ }^{28}$ There have been no quantitative findings to date, relative to muscle endurance, strength and power to support the use of whole body cryotherapy or partial body cryotherapy in aiding recovery from exercise..$^{28}$

\section{Conclusion}

Cryosauna is a relatively new and safe modality to be used when the benefits of cold therapy are wanted. There are several way to deliver cold to the body, however, these all use water as the medium and just treat 1 or 2 parts of the body. A way to treat the whole body with dry cold is with Whole Body Cryotherapy. Using this technique, it will provide for many positive physiological effects to a large area.

\section{Acknowledgements}

None.

\section{Conflict of interest}

Author declares that there is no conflict of interest.

\section{References}

1. Knight KL. Cryotherapy in Sport Injury Management. Human Kinetics. 1995;1(2):60-62.

2. Knight KL, Draper DO. Therapeutic Modalities: The Art and Science, 2nd ed. Wolters Kluwer, Lippincott Williams, Wilkins, USA; 2013.

3. Knight KL. Ankle rehabilitation with cryokinetics. Phys Sportsmed. 1979;7(11):113

4. Knight KL. Cryokinetics in rehabilitation of joint sprains. J Can Athl Ther Assoc. 1981;8(3):17-18.

5. Starkey JA. Treatment of ankle sprains by simultaneous use of intermittent compression of ice packs. Am J Sports Med. 1976;4(4):142-144.
6. Lehmann JF, Lateur BJ. Cryotherapy. In: Lehmann JF, editor. Therapeutic Heat and Cold, 3rd ed. Williams \& Wilkins, USA; 1982. p. 563-602.

7. Behnke RS. Cold therapy. J Athl Train. 1974;9:178-179.

8. Lehmann JF. Therapeutic Heat and Cold, 4th ed. Williams \& Wilkins: USA; 1982. p. 563-602.

9. Boykin JV, Crute SL. Mechanisms of burn shock protection after severe scald injury by cold-water treatment. J Trauma. 1982;22(10):859-866.

10. Rippe B, Grega GJ. Effects of isoprenaline and cooling on histamine induced changes of capillary permeability in rat hindquarter vascular bed. Acta Physiol Scand.1978;103(3):252-262.

11. Harris ED, McCroskery PA. The influence of temperature and fibri stability on degradation of cartilage collagen by rheumatiod synovial collagense. N Engl J Med. 1974;290(1):1-6.

12. Svanes K. Studies in hypothermia I. The influence of deep hypothermia on the formation of cellular exudate in acute inflammation in mice. Acts Anaesthesiol Scand. 1964;8:143-156.

13. Svanes K. Studies in hypothermia II. The influence of deep hypothermia on the formation of fluid exudate in acute inflammation in mice. Acts Anaesthesiol Scand. 1964;8:157-166.

14. Dorwart BB, Hansell JR, Schumacher HR. Effects of heat, cold and mechanical agitation on crystal-induced arthritis in the dog. Arthr Rheum. 1973;16(4):563-571.

15. Abakumova E. Effect of hypothermia on wound healing. Stomatologiia 1978;57(1):19-21.

16. Everall M. Cold Therapy. Nurs Times. 1976;72(4):144-145.

17. Haines J. A study into a report on cold therapy. Physiotherapy. 1970;56(11):501-502.

18. Raptou AD. Cryotherapy: a brief review. South Med J. 1978;61:625-627.

19. Knight KL, Londeree BR. Comparison of blood flow in the ankle of uninjured subjects during the therapeutic applications of heat, cold and exercise. Med Sci Sports Exerc. 1980;12(1):76-80.

20. Kraus H.Prevention and treatment of skiing injuries. J Trauma. 1961;1:457-463.

21. Chu DA, Lutt CJ. The rationale of ice therapy. J Athl Train. 1969;4:8-9.

22. Travell J, Rinzler SH. The myofascial genesis of pain. Postgrad Med. 1952;11(5):425-434.

23. Ashby EC. Abdominal pain of spinal origin. Ann $R$ Coll Surg Engl. $1977 ; 59(3): 242-246$.

24. Hopkins JT, Ingersoll CD, Krause BA, et al. Effect of knee joint effusion on quadriceps and soleus motoneuron pool excitability. Med Sci Sports Exer. 2001;33(1):123-126.

25. Hopkins JT, Stencil R. Ankle cryotherapy facilitates soleous function. $J$ Orthop Sports Phys Ther. 2002;32(12):622-627.

26. Ingersoll CD, Palmeiri RM, Hopkins JT. A joint dilemma. Rehabil Manag. 2003;16(1):38-42.

27. ESPNScrum Staff Warburton pushes through pain barrier. ESPNScrum.

28. Costello J, Baker P. Whole body cryotherapy (extreme cold air exposure) for preventing and treating muscle soreness after exercise in adults. Cochrane Database Syst Rev. 2015;18(9):CD010789.

29. Haussworth C, Schaal K. Parasympathetic activity and blood catecholamine and whole body cryostimulation. PLoS One. 2013;8(8):e72658. 
30. Kruger M, deMarees M . Whole body cryotherapy's enhancement of acute running performance in well-trained athletes. J Sports Physiol Perform. 2015;10(5):605-612.
31. Zalewski P, Bitner A, Słomko J, et al. Whole body cryostimulation increases parasympathetic outflow and decreases core body temperature. J Therm Bio. 2014;45:75-80. 